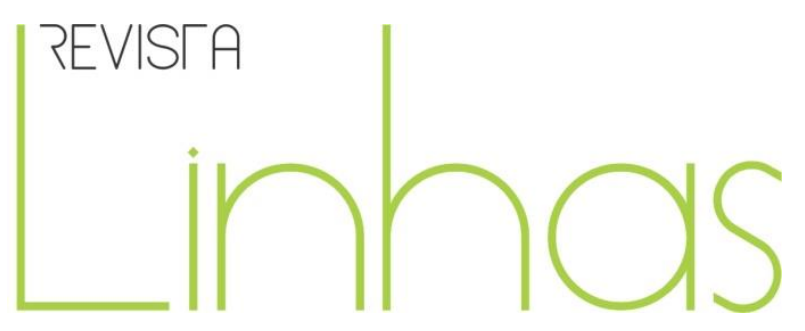

\title{
A política dos livros didáticos de história nas salas de aula sul- africanas na era do Curriculum $2005^{1}$
}

\begin{abstract}
Resumo
A África do Sul celebrou recentemente vinte anos da transição política do regime de apartheid para uma nação democrática. Uma das mudanças importantes nesta transição foi a reforma curricular, incluindo a natureza do conteúdo dos livros didáticos ensinado nas escolas Sul-Africanas pós-apartheid. Este artigo discute o conteúdo dos livros didáticos na era do Curriculum 2005, uma declaração nacional curricular introduzida em 1997 e posteriormente revista em 2002. Primeiramente, discuto a história sócio-política da educação na África do Sul, incluindo a transição do apartheid para o pós-apartheid como um contexto para esta análise. Em segundo lugar, descrevo as limitações de conteúdo dos livros didáticos de história, ensinado nas salas de aula pós-apartheid. Usando a teoria crítica, argumento que o conteúdo dos livros adotados recentemente não interrompeu de forma decisiva a histórica deturpação e sub-representação da história política de grupos marginalizados na África do Sul, embora alguns livros tenham feito mais progressos do que outros.
\end{abstract}

Palavras-chave: Livros Didáticos de História. África do Sul. PósApartheid. Curriculum 2005. Teoria Crítica.

\author{
Bekisizwe Ndimande \\ University of Texas at San \\ Antonio - UTSA - \\ San Antonio/Texas - United \\ States \\ bekisizwe.ndimande@utsa.edu
}

\begin{abstract}
Para citar este artigo:
NDIMANDE, Bekisizwe. A política dos livros didáticos de história nas salas de aula sul-africanas na era do Curriculum 2005. Revista Linhas. Florianópolis, v. 19, n. 41, p. 117-138, set./dez. 2018. Título original: The politics of history textbooks in South African classroom in the era of Curriculum 2005. Traduzido por Fernando Coelho, com revisão técnica de Eliane Peres.
\end{abstract}

DOI: $10.5965 / 1984723819412018117$

http://dx.doi.org/10.5965/1984723819412018117

'O Curriculum 2005 é a nova "base nacional comum curricular" que foi introduzida após o fim do apartheid no sistema de ensino na África do Sul em 1994. 


\title{
The politics of history textbooks in South African classroom in the era of curriculum 2005
}

\begin{abstract}
South Africa has recently celebrated twenty years of political transition from apartheid government to a democratic nation. One of the important changes in this transition was the reform of classroom curriculum, including the nature of textbook content taught in post-apartheid South African schools. This article discusses the textbook content in the era of Curriculum 2005, a national curriculum statement introduced in 1997 and subsequently revised in 2002. First, I discuss the socio-political history of education in South Africa, including the transition from apartheid to post-apartheid as a context to this analysis. Second, I describe the limitations of history textbooks content taught in post-apartheid classrooms. Using critical theory, I argue that the content of newly adopted history textbooks did not radically interrupt the longstanding misrepresentation and underrepresentation of the political histories of marginalized groups in South Africa, although some textbooks have made progress than others.
\end{abstract}

Keywords: History Textbooks. South Africa. PostApartheid. Curriculum 2005. Critical Theory. 
A África do Sul emergiu de décadas de domínio colonial e do regime do apartheid apenas 24 anos atrás. Esta nação de 52 milhões de pessoas sofreu uma das piores divisões e repressão política através do sistema chamado apartheid. Como resultado, a era do apartheid também produziu as desigualdades sociais que vão permanecer ainda por muitos anos. Negros/Africanos ${ }^{2}$, Indianos ${ }^{3}$ e Mestiços ${ }^{4}$ estavam na ponta dessas desigualdades e, assim, foram tratados como cidadãos de segunda classe. Todos os programas socioeconômicos foram projetados para criar disparidades entre diferentes grupos raciais. O acesso às oportunidades de mobilidade social era simplesmente baseado em raças. A educação passou a desempenhar um papel importante neste tipo de engenharia social. Por exemplo, as escolas públicas sob o regime do apartheid, não eram apenas segregadas por raça, a alocação de fundos entre escolas brancas e não-brancas era também muito desigual. O objetivo era manter a hierarquia racial que assegurou que as populações não-brancas continuassem a ser tratadas como cidadãos de segunda classe. Além disso, o conteúdo curricular representava o que Apple (1993) chama de “currículo oculto e os efeitos de livros didáticos", a fim de avançar com a ideologia do apartheid. Não é preciso dizer que o apartheid gerou uma resistência política feroz dos grupos oprimidos, que o governo reprimiu com ações militares brutais.

Somente em 1994 a África do Sul realizou suas primeiras eleições democráticas, nas quais Rolihlahla Nelson Mandela foi eleito presidente. É inegável que a introdução da democracia neste país foi uma vitória parcial dos grupos marginalizados, historicamente oprimidos pelos sistemas colonial e do apartheid. As mudanças na esfera da educação tornaram-se ainda mais importantes ao proporcionar melhores oportunidades educacionais e condição de vida a muitas pessoas que foram empobrecidas sob o regime do apartheid. Embora essas mudanças sócio-políticas fossem importantes para a

\footnotetext{
2 Para o propósito deste artigo, eu uso os termos Negro e Africano [Black and African] indistintamente. Neste contexto, ambos os termos representam grupos Indígenas [Aborígenas] cujos descendentes são do continente africano.

${ }^{3}$ Indianos [Indians] se referem aos descendentes de imigrantes da Índia colonial que foram trazidos para a província de Natal pelos colonialistas britânicos como trabalhadores contratados em plantações de canade-açúcar em meados do século XIX.

${ }^{4} \mathrm{O}$ termo Mestiço [Coloured] foi usado pelo governo do apartheid como categoria racial para se referir as comunidades de raça mista na África do Sul.
} 
educação, estavam longe de serem benéficas. Como defendo neste artigo, houve algumas limitações e desafios que vieram junto com a reforma curricular e dos livros didáticos.

Para efeito deste artigo, concentro a atenção na política de conteúdo dos livros didáticos na era da reforma curricular conforme o Curriculum 2005. Os argumentos foram concebidos em várias partes. Primeiro, discuto aspectos da história da educação na África do Sul conforme foi implementada durante o apartheid, incluindo a transição política para o pós-apartheid. Em segundo lugar, examino o Curriculum 2005, incluindo a sua limitação na reforma curricular. Analiso o conteúdo de livros didáticos para ilustrar limitações e possíveis melhorias do que é ensinado nas salas de aula, em especial para alunos dos grupos historicamente marginalizados. Em terceiro lugar, utilizo a teoria crítica para fazer afirmações que livros didáticos vazios de conteúdo crítico podem ser voltados para resguardar o status quo de colônia, especialmente em nações com histórico de colonialismo e opressão. Baseado no conteúdo dos livros didáticos de história analisados, concluo que os mesmos, adotados após o apartheid, e a reforma curricular, não interromperam de forma decisiva a histórica deturpação e sub-representação da história política de grupos marginalizados na África do Sul.

\section{O contexto da educação sob o regime do apartheid na África do Sul}

O apartheid foi institucionalizado na África do Sul em 1948 como um sistema de governo hegemônico projetado para impor a segregação racial e legitimar a supremacia branca (BIKO, 2002; LODGE, 1983; MARKS \& TRAPIDO, 1987; MOTHLABI, 1985). Esse regime reforçou, por exemplo, a ideia de grupos raciais e de uma sociedade racialmente segregada. Este sistema de governo criou quatro categorias raciais que também foram estratificadas em termos de suas relações com as estruturas sociais. O termo Negro foi usado para se referir aos povos indígenas da África do Sul; Mestiço, para os povos de raça mista; Indiano, para os povos trazidos da Índia para a África do Sul em 1800, pelo governo colonial britânico para trabalhar como escravos em canaviais; e Branco, para aqueles que originalmente vieram da Europa e outros países ocidentais durante a colonização da África do Sul no início dos anos 1600. 
Esta classificação racial sob o apartheid garantiu que a supremacia branca e privilegiada na África do Sul fosse mantida, enquanto Negros, Indianos e Mestiços eram tratadas como cidadãos de segunda classe. De acordo com as Estatísticas da África do Sul (2011), o país tem uma população de 52 milhões de pessoas em nove províncias. Essa nação tem quatro categorias raciais que foram criadas pelo apartheid após 1948 para alcançar os objetivos de manter uma hierarquia racial, que são assim distribuídos em porcentagens: Negros (79,2\%), Mestiços (8,9\%), Indianos (2,5\%) e Brancos (9,6\%).

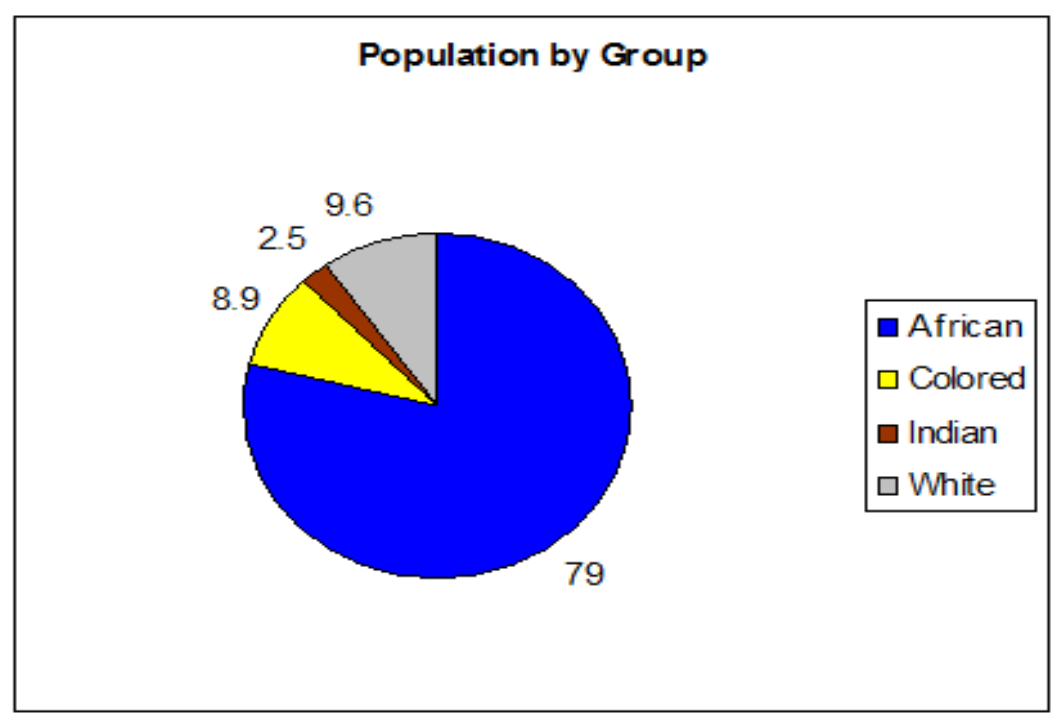

Figura 1 - Gráfico da população por grupo - Negros/Africanos, Mestiços, Indianos e Brancos Fonte: Estatísticas da África do Sul, 2011

Sob o apartheid, a educação passou a desempenhar um papel importante na manutenção dessas desigualdades sociais. Hendrik Frensch Verwoerd, Ministro de Assuntos Nativos em 1950 e Primeiro-ministro em 1958, apresentou o projeto de lei de Educação Bantu em um Parlamento exclusivamente branco. Educação Bantu era um sistema de ensino oferecido aos negros. A distinção entre a Educação Bantu e a educação do apartheid é: enquanto a educação do apartheid agrupava o sistema de ensino opressivo "oferecido" para Negros, Indianos e Mestiços coletivamente, a Educação Bantu foi especificamente "oferecida" para negros através do Departamento de Assuntos Nativos, que mais tarde foi renomeado como Departamento de Educação Bantu. Verwoerd acreditava que os negros deveriam ser subjugados através da educação para impor a ideologia do apartheid. Ao analisar a Educação Bantu, Christie e Collins (1984) 
afirmam que este sistema de ensino foi de longe o mais repressivo que a África do Sul já experimentou,

[Ele] estipulava que todas as escolas negras teriam que ser registradas junto ao governo, e que o registro ficaria a critério do Ministro. Esta medida permitiu que o governo encerrasse quaisquer programas educacionais que não apoiassem seus objetivos... A Lei deu amplos poderes ao Ministro da Educação Bantu, incluindo o controle sobre os professores, os programas [planos de estudos] e qualquer outra questão relacionada com o estabelecimento, a manutenção, a gestão e o controle sobre as escolas Bantu do governo. (CHRISTIE; COLLINS, 1984, p. 171)

Christie e Collins (1984) explicam ainda que, em 1959, praticamente todas as escolas para negros (exceto para as poucas escolas Católicas) tinham sido postas sob o controle central do Departamento de Assuntos Nativos e conduzidas de acordo com as leis de Educação Bantu.

A Educação Bantu era de fato o aparelho ideológico do Estado (Althusser, 1971) utilizado durante o apartheid para manter o status quo de discriminação racial e as desigualdades sociais, marginalizando os negros sul-africanos por muitos anos. 0 conteúdo curricular representava o que Enslin (1990) chamou de "Pedagogia Fundamental" para descrever um curriculum e um conteúdo tendenciosos impostos nas salas de aula para os negros e em programas de preparação de professores negros para suprimir e minar o pensamento crítico. Não foi nenhuma surpresa que os estudantes negros tiveram uma taxa de abandono desproporcionalmente alta durante este tempo. De acordo com Hartshorne (1992), só em 1988, 307.000 estudantes negros deixaram a escola não tendo passado da primeira fase, e cerca de 440.000 da segunda fase do ensino fundamental ${ }^{5}$.

Este sistema continuou por muitos anos, mas também havia resistência contra o apartheid. A luta contra o apartheid também foi testemunhada na educação, na batalha por um currículo melhor. O final dos anos 1980 e início dos anos 1990 foram cruciais para a mudança gradual em direção à democracia. Segundo Ndimande (2012), após as eleições democráticas de 1994, o governo pós-apartheid instituiu uma Constituição democrática (1996) que estabeleceu uma série de mudanças progressivas com o objetivo de corrigir as

\footnotetext{
${ }^{5}$ Para uma discussão aprofundada sobre o apartheid e a Educação Bantu, consulte Kallaway (1984).
} 
desigualdades anteriores criadas pelo regime do apartheid. Além disso, o Ato das Escolas Sul-Africanas (SASA, em inglês, South African Schools Act), de 1996, foi aprovado para revogar todas as formas de legislação do apartheid sobre educação e substituí-las por um sistema escolar uniforme, que aprove a transformação democrática da sociedade sulafricana e combata o racismo, o sexismo e todas as outras formas de discriminação (SASA, 1996, 2A-3). O objetivo deveria ser alcançado através da instauração de um sistema uniforme não-racial de educação, em termos de organização escolar, governança e financiamento, incluindo os aspectos curriculares, como a escolha de livros didáticos e de seu conteúdo.

No centro de todas essas mudanças democráticas estava a implementação do Curriculum 2005, a nova base nacional comum curricular cujo objetivo era abordar estas desigualdades históricas no conteúdo do currículo e da pedagogia, incluindo a adoção de novos livros didáticos.

\section{Curriculum 2005 e a Reforma Curricular e dos livros didáticos}

Pouco mais de um ano depois do Ato das Escolas Sul-Africanas ser anunciado, Sibusiso Bhengu, ex-ministro da Educação, lançou, em 1997, uma nova base curricular conhecida como Curriculum 2005, que foi desenvolvido tendo como modelo a Educação Baseada em Resultados. De fato, o Curriculum 2005 deveria ser uma substituição ideal para o currículo racista e colonialista que dominou a maioria das salas de aula da África do Sul por décadas. Além disso, a grade do Curriculum 2005 foi o esforço do novo governo em direção à democratização do ensino público, incluindo o currículo e a adoção de diferentes livros didáticos. O propósito foi o de corrigir as desigualdades educacionais do sistema de ensino do apartheid. Muitos educadores, alunos e pais, especialmente das escolas e comunidades de Negros, Mestiços e Indianos saudaram a nova estrutura curricular com aplausos. Em outro estudo observei que tal entusiasmo era bastante compreensível em um país onde a maioria dos cidadãos suportou o peso das desigualdades na educação (NDIMANDE, 2000).

No entanto, a motivação trazida pelo anúncio do Curriculum 2005 durou pouco tempo. Após a sua implementação em 1997/98, a nova grade curricular teve muitos 
desafios em termos de cumprimento das metas que se pretendia alcançar. O problema era que a nova grade curricular foi amplamente inspirada na Educação Baseada em Resultados. Ela está enraizada na crença de que os "resultados" podem ser utilizados como medida de responsabilidade e como um meio de avaliar a qualidade e o impacto do ensino (NDIMANDE, 2010). Isso resultou em uma crítica séria que mostra como o Curriculum 2005, baseado em "resultados", segue uma abordagem de mercado neoliberal à reforma curricular.

Como Lubienski e Ndimande (2017) argumentam, o mecanismo de mercado neoliberal na reforma curricular tem impacto negativo sobre a igualdade, em particular na sua incapacidade de superar as injustiças históricas na educação. As políticas das escolas públicas e os modelos de currículo influenciados pela ideologia neoliberal podem perpetuar a marginalização de comunidades historicamente desfavorecidas, neste caso as comunidades negras, mestiças e indianas na África do Sul. Na verdade, concordo com a alegação de Jansen (1999), que afirma que este modelo de grade curricular baseado em resultados falhou ao trazer um legado histórico positivo suficiente para a reforma curricular pós-apartheid ${ }^{6}$.

Poucos anos depois, as críticas ao Curriculum 2005 e suas características baseadas em resultados colocaram o governo sob enorme pressão para formar um Grupo de Trabalho chamado Comitê de Revisão do Curriculum 2005 para simplificar a Educação Baseada em Resultados e sua implicação (CHISHOLM, 2000). Mesmo assim, o foco do Comitê não foi avaliar o impacto adverso da Educação Baseada em Resultados, mas simplificar os resultados da aprendizagem em vez de questionar a filosofia da política, em especial o seu conteúdo curricular (NDIMANDE, 2010).

\section{A política do conteúdo do currículo e dos livros didáticos na África do Sul pós-apartheid}

Essa seção começa reconhecendo algumas vitórias parciais realizadas e conquistadas nas reformas do ensino pós-apartheid. Por exemplo, algumas escolas deixaram de ser segregadas e o financiamento das escolas públicas, historicamente

\footnotetext{
${ }^{6}$ Para mais detalhes sobre a Educação Baseada em Resultados, consulte Jansen \& Christie, 1999.
} 
subfinanciadas, aumentou; enfim, o Curriculum 2005 foi introduzido para substituir as políticas curriculares do apartheid. Embora ainda não tenham melhorado plenamente as circunstâncias da educação das comunidades marginalizadas e de seus filhos, essas mudanças na educação estão na direção certa, são vitórias parciais, uma vez que sob a educação do apartheid estudantes Negros, Mestiços e Indianos enfrentaram condições educacionais adversas.

Nesta seção, no entanto, a atenção está voltada às limitações e aos desafios do currículo e do conteúdo dos livros didáticos que ficou evidente no novo quadro curricular. Examino especificamente o conteúdo de livros didáticos das primeiras reformas pósapartheid. Defendo que o conteúdo do livro no início da reforma curricular pós-apartheid produziu, em essência, um conhecimento histórico tendencioso a favor do grupo dominante e da ideologia colonialista, em vez de questionar de forma contundente as histórias não contadas de dominação política. Defendo ainda que tal conteúdo dos livros didáticos não consegue interromper a histórica deturpação e sub-representação das histórias políticas de grupos marginalizados na África do Sul.

O primeiro conteúdo de livros didáticos de história analisado neste artigo foi usado nos primeiros anos da reforma curricular pós-apartheid, ou seja, após a introdução do Curriculum 2005. O conteúdo do livro didático em discussão foi representado no programa intitulado: History Syllabus, Higher Grade Standard 8-10 que foi distribuído pelo Ministério da Educação em 2000. Deixo claro que a minha avaliação sobre o conteúdo do livro didático de história não foi uma pesquisa exaustiva. Aconteceu especialmente em uma visita informal à Escola Secundária Ematsheni ${ }^{7}$, no início do ano letivo de 2001. Enquanto estava na escola, fiquei impressionado com o conteúdo dos livros didáticos, cujo teor analisei criticamente.

Revendo esse documento, pois se assemelha ao conteúdo do livro didático de história, achei que não era um texto de abordagem crítica, adequado a uma sala de aula pós-apartheid. O conteúdo foi dividido em duas seções, ou seja, História Geral e História da África do Sul. A primeira parte é composta pela "toda-poderosa" história da Europa/Estados Unidos, com foco em Lenin, Stalin, o “New Deal” de Roosevelt, a

\footnotetext{
${ }^{7}$ O nome da escola é fictício. Na verdade, esta foi a mesma escola onde realizei minha prática de ensino enquanto estudava para me tornar professor.
} 
Doutrina Monroe, Relações Internacionais, Guerra Fria, e assim por diante. Mais uma vez, não pretendo argumentar que tal história é desnecessária, mas o conteúdo crítico se daria, por exemplo, caso o livro didático fizesse uma análise de como Lenin ou Roosevelt estariam relacionados à política sul-africana e/ou como esses personagens europeus moldaram a política do mundo a ponto de impactar a África do Sul.

Durante a educação do período do apartheid, todos os livros de história começavam pela história europeia. Isso precisa ser contestado. Questionamentos precisam ser feitos sobre a estrutura do conteúdo dos livros didáticos. Na verdade, tornase ideologicamente questionável quando o conteúdo da história da Europa/EUA fica alocado na primeira seção de um livro didático. E é questionável por duas razões. Primeiro, porque assume que a história da Europa/EUA é melhor do que a história dos Indígenas da África do Sul. Segundo, porque há tempo suficiente para a história da Europa/EUA ser ensinada até o fim, enquanto a seção da África do Sul é apressada especialmente pela proximidade do fim do semestre.

Um tema separado chamado África desde a Segunda Guerra Mundial levanta questões ainda mais preocupantes: Por que um livro começa a história africana neste período específico? Este foi aproximadamente o período de descolonização da África. Como os estudantes aprenderiam sobre as lutas dos países colonizados durante a era colonial se a própria documentação do colonialismo fosse encoberta? Como compromisso, o texto menciona, superficialmente, é claro, os movimentos pela independência na África e a ascensão do nacionalismo como forma de introdução ao tema. Isso é uma forma de diminuir a importância de tal história. Um livro didático de história deve ser crítico, especialmente em um país como a África do Sul que foi colonizado pelos ingleses e holandeses. Essa história colonial deve ser ensinada em uma discussão crítica para que os alunos possam entender a história da raça e da opressão racial que continuam a existir no país.

É importante salientar também que independente do propósito do tema, ao abordar ou não a África desde a Segunda Guerra Mundial, um livro de história representativo deve expor um contexto histórico e político sobre como as sociedades africanas foram moldadas por forças colonizadoras e pelo colonialismo (antes e depois da Segunda Guerra Mundial). Sem mencionar ou mesmo aludir que tais eventos 
representam uma total deturpação do pensamento e da filosofia africana. Também impressiona o fato de que os livros didáticos falam sobre a descolonização da África, mas não criticam a colonização. A linguagem do livro didático dá uma impressão enganosa, como se a descolonização da África tivesse sido um presente. Há pouca menção à honrosa luta de mulheres e homens cuja pressão contra o colonialismo foi intensa. Além disso, o livro fala sobre os desafios comuns que os Estados africanos independentes enfrentam, no entanto, não menciona o neocolonialismo existente nessas "ex-colônias". Pergunta-se: Os alunos devem ser impedidos de estudar os efeitos do neocolonialismo, que, a propósito, assumiu novas formas, a saber, a privatização e a mercantilização do estado? Defendo que, a menos que a história seja ensinada criticamente, os alunos não se envolverão com os acontecimentos históricos de forma crítica.

Existe uma notável omissão de fatos importantes da história Africana neste livro, por exemplo, a discussão do tráfico de escravos da África para a Europa e as Américas está ausente. No livro A People's History of the United States, Howard Zinn (2005, p. 27) escreve que "a escravidão nos Estados africanos muitas vezes foi usada pelos europeus para justificar seu próprio comércio de escravos". Posteriormente, Zinn aponta que a escravidão africana foi desumana e não precisa ser exaltada. No entanto, segundo esse autor, era muito diferente da escravidão nas plantações e nas minas nas Américas, que era incapacitante ao longo da vida. Segundo Zinn, por volta do ano de 1800, de 10 a 15 milhões de negros africanos tinham sido transportados para a Europa e a América:

Primeiro, os holandeses, depois os ingleses dominaram o tráfico de escravos. (Em 1795, a cidade de Liverpool tinha mais de cem navios negreiros que foram responsáveis por metade de todo o comércio de escravos Europeu). Alguns americanos na Nova Inglaterra entraram no negócio, e em 1637, o primeiro navio de escravos americanos, o Desire, partiu de Marblehead... Estima-se que a África perdeu 50 milhões de seres humanos à morte e à escravidão nestes séculos, pelas mãos de traficantes de escravos e fazendeiros na Europa Ocidental e na América, os países considerados mais avançados do mundo. (ZINN, 2005, p. 29)

Esta história narrada por Haward Zinn, que deve ser considerada importante em um país como a África do Sul que foi colonizado por holandeses e ingleses, ainda está ausente dos livros de história. 
Como mencionado acima, a história sul-africana aparece apenas na segunda parte do texto. A primeira parte desta história abrange o período de 1924 a 1948. Concentra-se em tópicos tais como os partidos políticos "brancos" e as eleições "brancas", as políticas econômicas, o reconhecimento da língua africâner, as políticas raciais de Hertzog, a grande depressão, os efeitos da Primeira Guerra Mundial na política da África do Sul, os movimentos trabalhistas, as eleições de 1948, entre outros. Com o Congresso Nacional Africano em funcionamento desde o início 1912, e com a mobilização ativa contra o apartheid em curso, a denominada Campanha do Desafio, de 1953, por exemplo, é outra omissão no conteúdo histórico da África do Sul.

Um dos problemas em tal conteúdo de história que começa com os europeus na África do Sul (partidos políticos "brancos" e eleições "brancas”) é a suposição de que a história do país começou com a chegada dos colonizadores europeus. Esta história contada oferece apenas a narrativa do colonizador. Ndimande e Neville (2015, p. 4) argumentam que uma história da África do Sul que começa com a chegada dos holandeses e ingleses é problemática:

A nação hoje conhecida como África do Sul, existia há milhares de anos antes da "descoberta" pela Europa. A África do Sul pré-colonial foi povoada por diversos grupos aborígenes que migraram do leste da África Central, os grupos de caçadores-coletores que eventualmente conseguiram chegar no extremo sul do continente. A chegada dos colonizadores europeus para estabelecer a Colônia do Cabo foi o começo da conquista e da usurpação da terra aborígene.

A seção de história da África do Sul também destaca o período de 1976 a 1994. A discussão desse período no texto se assemelha a um complemento da história, ou seja, uma discussão história sem substância, mas com alguns poucos eventos adicionados aqui e ali, sem profundidade e engajamento crítico. Ainda piores são as instruções sobre o currículo de história, nas quais pode-se ler: "2.3. o período 1976-1994 (não é matéria de prova)", que significava que os alunos não seriam examinados sobre este tema. Dada a importância deste período na história da política sul-africana, um período de campanha mundial contra o apartheid, ele poderia ser tratado como um complemento no livro didático? Uma vez tratado como um complemento, e não sendo exigido para fins de exame, isso pode gerar um desinteresse dos alunos nesta parte da história em particular. 
Apple (1996) refere-se a este tipo de conteúdo curricular como uma "tradição seletiva", que significa que somente o conteúdo considerado necessário pelo grupo dominante poderia ser selecionado para ser ensinado e/ou enfatizado no currículo.

No contexto sul-africano, isso mostra como os livros didáticos de história, mesmo depois do apartheid, ainda são guiados com base na filosofia e nas percepções dos brancos. Livros didáticos que são racialmente tendenciosos refletem uma das características do neocolonialismo - a tentativa de apagar a memória coletiva dos povos oprimidos. Também precisa ser salientado que é irônico quando os eventos que levaram às eleições democráticas de 1994, são tratados como história adicional nas salas de aula da África do Sul, ainda que esses eventos foram marcantes nacional e internacionalmente, especialmente depois que o presidente Mandela foi eleito o primeiro presidente democrático do país.

É necessário mencionar aqui que a terrível situação do conteúdo didático nas salas sul-africanas da era pós-apartheid finalmente chamou a atenção do ex-ministro da Educação três anos após a adoção de livros didáticos no período citado. $\mathrm{O}$ ex-ministro Kader Asmal, posteriormente fixou um prazo de dois anos para a publicação de um novo conjunto de livros didáticos de história, incluindo um sobre o apartheid. Além deste prazo, Kader Asmal lançou o Projeto História da África do Sul, para supervisionar o processo de transformação do ensino de história em todas as escolas (MTSHALI, 2002). Embora o Ministério precise ser elogiado pelo esforço de transformar o conteúdo dos livros didático de história, o projeto foi concluído com uma melhoria mínima no conteúdo na direção de uma história crítica da África do Sul. Em outras palavras, embora alguns livros tenham acrescentado tópicos importantes, nenhum era crítico o suficiente para conscientizar os alunos sobre suas identidades e lutas sócio-políticas, como deveria ser. Dois exemplos podem ser utilizados para detalhar esse ponto.

O primeiro exemplo, é de um livro de 2007 que foi adotado após o Projeto História da África do Sul ser concluído. O título do livro é New Generation History Grade 12. A estrutura do conteúdo desse livro é preocupante, pois a história da Europa está logo no início. As implicações de um livro didático de História da África do Sul que começa com a história dos países europeus, em vez da história sul-africana, já foram tratadas neste artigo. Isso mostra o papel dominante que o discurso europeu desempenha no currículo 
das salas de aula sul-Africanas. Mas o mais importante, como o livro analisado anteriormente neste trabalho, este texto de história omitiu as atrocidades da colonização, incluindo a escravidão na colônia do Cabo (MOLTENO, 1984) e na África (ZINN, 2005). A seção sobre o Protesto da Sociedade Civil é problemática porque começa abordando os protestos contra guerras e opressão das sociedades civis nos EUA e na Europa. Os protestos contra o apartheid são colocados no final desta seção e os eventos são vagamente discutidos. O fato de títulos como o Apartheid e Movimento Antiapartheid não aparecerem, é por si só problemático, no sentido que parece haver uma falta de vontade até mesmo para nomear o apartheid.

O segundo exemplo é o livro adotado Viva History Learner's Book Grade 10. Este livro em especial traz um fio de esperança na transformação do conteúdo de história. Há um número de tópicos críticos recentemente incluídos que se relacionam com os contextos socioeconômicos e políticos da África do Sul. No primeiro capítulo, há uma unidade sobre os Aborígenes Africanos, seguido pelo impacto da conquista europeia, a guerra e o início do colonialismo nas Américas, África e Índia, incluindo uma unidade sobre o comércio de escravos. A diferença do conteúdo deste livro está na estrutura que não segue a forma dominante, que inicia contando a história da África do Sul com a chegada dos europeus. A crítica quanto a exibição do corpo da mulher [da etnia] Khoisan, Sarah Baartman pelos colonizadores britânicos, que transportaram sua estátua para a Inglaterra em 1810 (HORNER; HATTINGH; VAN SCHALKWYK; SELLO, 2005) para exibir publicamente uma mulher africana sem roupa, não é apenas a mostra da objetificação dos corpos das mulheres, mas daqueles que foram colonizados. Este é um dos poucos livros didáticos de história com os quais me deparei até agora, dispostos a mergulhar em um conteúdo tão importante para ajudar os alunos a aprender sobre como a história os representa, sobretudo aqueles das comunidades marginalizadas. Como os autores escreveram na sobrecapa, “este livro aborda a visão eurocêntrica da história da África”.

\section{A Teoria Crítica na análise do conteúdo de livros didáticos}

Para o propósito da análise dos problemas do conteúdo de livros didáticos na África do Sul, me baseio na teoria crítica e nos estudiosos críticos para entender o 
impacto sobre esta situação nas comunidades. A teoria crítica é um campo amplo que inclui contribuições da Escola de Frankfurt, tradições Marxistas e Neomarxistas, Teorias da Democracia, Tradição Feminista, Teorias Pós-coloniais, entre outras (POPKEWITZ, 1999; TORRES, 1999). Enquanto a teoria crítica identifica, associa e traça suas raízes originais à Escola Marxista Alemã de Frankfurt na década de 1920, seus usos e evolução desafiaram as análises e estruturas essenciais e tendenciosas nas Ciências Sociais ${ }^{8}$. Neste artigo, o termo teoria crítica é usado no contexto do campo educacional, abordagem que ganhou impulso na década de 1970 e ao longo da década de 1990 nos Estados Unidos e na Europa, que teve influência sobre estudiosos educacionais em outros países também. A teoria crítica nesta discussão tem base nos trabalhos de intelectuais e teóricos como Gramsci (1971), Freire (1970), Althusser (1971), Apple (1979), Young (1975), Giroux (1983), McLaren (1995), Popkewitz (1995), Torres (1999), entre outros. Desse modo, a análise crítica é necessária e crucial nesta discussão sobre o conteúdo de livros didáticos para trazer mudanças políticas no currículo escolar que possam ser orientadas para a justiça social e que defendam um currículo mais inclusivo na sala de aula.

Através da lente da teoria crítica, Apple (1996) lembra que a educação não é um fenômeno neutro. De acordo com o autor: "Ela é produzida a partir de conflitos culturais, políticos e econômicos, tensões e compromissos que organizam e desorganizam um povo" (p. 22). Assim, precisamos fazer perguntas sérias sobre o conhecimento incluído ou excluído nos livros de história. Os pais e os indivíduos de grupos dominantes tendem a ter influência na política da escola em virtude do poder político e econômico que possuem, excluindo grupos marginalizados (APPLE, 1996). A discussão neste artigo, do currículo na era do apartheid e do conteúdo dos livros didáticos no Curriculum 2005 é um exemplo de como o conteúdo do currículo é uma contestação que reproduz as tensões que organizam e desorganizam as pessoas. Tal tensão se manifesta através da adoção de livro didáticos e de seus conteúdos (CORNBLETH; WAUGH, 1995).

Por muitas décadas, a história do currículo escolar na África do Sul e em outros países, como Estados Unidos, Brasil, Namíbia e Reino Unido, tem sido caracterizada por um conteúdo que tem produzido e reproduzido as desigualdades sociais (APPLE, 1979; BOWLES \& GINTIS, 1976; FREIRE, 1970; GIROUX, 1983; KALLAWAY, 1984; NKOMO, 1990;

\footnotetext{
${ }^{8}$ Consulte Torres (1999), principalmente p. 91.
} 
YOUNG, 1971; ZEICHNER AND DAHLSTROM, 2001). O currículo escolar, em seus livros de caráter tendenciosos e colonialistas, usaram o conteúdo do currículo para excluir as vozes do subalterno (SPIVAK, 1988), isto é, aqueles que estão fora da hegemonia sociocultural e política dos impérios coloniais, subjugados e colonizados. Em outras palavras, o conteúdo curricular, principalmente através de livros didáticos, aderiu e seguiu rigorosamente a transmissão do cânone, que supostamente era para ser consumida pelos estudantes de forma acrítica e incontestável como se esse conhecimento representasse a "verdade universal” para todos na sala de aula. Apple (1993), Lowen (1995) e Zinn (2005), entre outros, argumentam que a própria produção de conhecimento era problemática, como no caso de conteúdos dos livros didáticos que criaram dogmas e distorções históricas ensinadas e aceitas sem muito debate nas salas de aulas. De modo geral estas têm sido as formas do currículo convencional que falharam ou deixaram de reconhecer os grupos historicamente marginalizados, bem como os diferentes contextos sócio-político das escolas públicas (Ibid.)

A análise de Michael Apple sobre a política de conteúdo curricular é útil para compreender aspectos do controle dominante, no que ele chama de conteúdo de livros didáticos como uma forma de controle curricular. Ainda segundo Apple (1993), é através de livros didáticos que o "conhecimento oficial” da escola é revelado. Sua análise sobre a política dos livros didáticos nos ajuda a entender que este conteúdo é cercado de controvérsias sobre o que é incluído e excluído nos textos:

Os textos são, na verdade, mensagens para e sobre o futuro. Como parte do currículo, eles integram nada menos do que o sistema de conhecimentos organizados da sociedade. Criando o que essa tem reconhecido como legítimo e verdadeiro. Ajudando a estabelecer os dogmas e, como tal, a recriar um ponto de referência importante para o que o conhecimento, a cultura, a crença e a moral realmente são. No entanto, tal afirmação... é enganosa de várias maneiras. Pois não foi uma "sociedade" que criou tais textos, mas grupos específicos de pessoas. (APPLE, 1993, p. 49)

É preciso salientar que uma das influências teóricas nas lutas contra a educação do regime do apartheid na África do Sul foram os estudos de Paulo Freire. Embora seu livro inovador, Pedagogia do Oprimido, tenha sido banido na África do Sul na década de 1970 e 
1980, como foi no Brasil, no entanto, em algum momento enquanto esteve exilado, suas ideias foram capazes de chegar na África do Sul ${ }^{9}$. Como um dos estudiosos proeminentes da tradição crítica, Paulo Freire (1970) escreve sobre a problemática do conteúdo do currículo e da pedagogia que tendem a marginalizar grupos oprimidos, assim como os Negros, os Mestiços e os Indianos, historicamente marginalizados na África do Sul. Ele argumenta que o currículo que atende aos grupos oprimidos é caracterizado pelo conhecimento tendencioso em favor da classe dominante, ou seja, é inclinado para os grupos dominantes que controlam o conteúdo do currículo, incluindo o dos livros didáticos.

Usando a teoria crítica como uma lente, Freire argumenta que um currículo escolar desprovido ou com a realidade histórica distorcida levou à desumanização das pessoas, cuja perspectiva é que elas percam o senso de sua história e da identidade. Isto serve para criar uma sociedade estratificada onde o poder não é dividido igualmente entre as comunidades. Neste contexto, argumenta Freire, os dominantes, aqueles que ele chamou de opressores, agem subjugando outros, os oprimidos.

Devido a essas desigualdades generalizadas, Freire argumenta que os alunos cujo conhecimento não está representado nos livros didáticos e no conteúdo curricular podem se perceber menos legítimos e indignos de papéis de liderança e, para ser mais preciso, perdem seu senso de identidade e de sua história. Isso perpetua a ignorância sobre suas condições socioeconômicas e políticas. A proposta de Freire, ao contrário, é uma educação libertadora que instiga os alunos a desafiar o conteúdo curricular e criar possibilidades críticas para mudar o mundo. A educação libertadora não omiti certas histórias ou fornece conteúdo histórico tendencioso ao grupo oprimido e suas comunidades, mas os ajuda a apoiar lutas mais amplas pelo reconhecimento cultural, político, econômico, de gênero e social.

Na Pedagogia do Oprimido, Freire afirma que essa é a pedagogia das pessoas envolvidas na luta pela sua própria libertação. Este é um dos princípios fundamentais de Freire de educação crítica, um currículo voltado para a justiça:

\footnotetext{
${ }^{9}$ Veja Nekhwevha, 2002.
} 
Nenhuma pedagogia que seja verdadeiramente libertadora pode permanecer distante do oprimido, tratando-os como infelizes e apresentando-os aos seus modelos de emulação entre os opressores. Os oprimidos devem ser o seu próprio exemplo na luta pela sua redenção.

(FREIRE, 1970, p. 39)

As escolas devem ser lugares de autonomia sócio-política, econômica e intelectual, e não desumanizar aqueles com menos poder e tratá-los como objetos. Neste contexto, livros didáticos de história têm o dever de questionar a dicotomia sujeitos versus objetos no currículo e na pedagogia para que os educadores e estudantes possam igualmente participar na aprendizagem em sala de aula. Os estudantes, em especial, devem ser encorajados a pensar criticamente e, assim, se envolver no que Freire chama de processos de "leitura do mundo."

\section{Considerações finais}

A discussão sobre o conteúdo dos livros didáticos de história na África do Sul pósapartheid mostra que o mesmo está longe de ser animador. Isso mostra que as nações que surgiram a partir de uma longa história de opressão política, incluindo a negação de oportunidades educacionais, podem ter dificuldades em seu processo de reforma curricular. Nesse caso, o contexto sociopolítico criou o que Ladson-Billings (2006) chama de "dívida educacional”, que significa que, a menos que um esforço conjunto seja feito para transformar o currículo, seria difícil superar um currículo que represente erroneamente o conhecimento e a história dos povos aborígenes nessa nação.

A introdução do Curriculum 2005 foi um passo na direção certa, mas esta grade nacional curricular pós-apartheid não adotou livros que questionem essa história tendenciosa. O único livro didático que tentou desvendar a história colonial traz alguma esperança. Na verdade, os estudiosos da tradição crítica podem contribuir com ideias para o empoderamento do conteúdo curricular dos livros didáticos, incorporando assim a história das comunidades historicamente marginalizadas, trazendo-o para o cerne dos livros de história. 


\section{Agradecimentos}

Gostaria de agradecer à equipe editorial da Revista Linhas por traduzir este artigo do inglês para o português, incluindo sua diligente revisão em ambos os idiomas. Também gostaria de agradecer aos revisores anônimos. Sou grato a Eliane Peres, Chris A. A. Ramil, Vera Lúcia Gaspar da Silva e Karla Cristina F. P. Koerich, que me motivaram a escrever e submeter este manuscrito para revisão por pares nesta revista.

\section{Referências}

ALTHUSSER, Louis. Lenin and philosophy and other essays. New York, NY: Monthly Review Press, 1971.

APPLE, Michael Whitman. Cultural politics and education. New York: Routledge, 1996.

APPLE, Michael Whitman. Ideology and curriculum. London: Routledge and Kegan Paul, 1979.

APPLE, Michael Whitman. Official knowledge: Democratic education in a conservative age. New York: Routledge, 1993.

BIKO, Steve. I write what I like: Selected writings. Chicago, IL: The University of Chicago Press, 2002.

BOWLES, Samuel and GINTIS, Herbert. Schooling in capitalist America: Educational reform and the contradictions of economic life. United States of America: BasicBooks, 1976.

CHISHOLM, Linda. C2005 and the Policy Process. Paper presented the Kenton Education Association. Port Elizabeth, South Africa, October 26, 2000.

CHISHOLM, Linda. Continuity and change in education policy research and borrowing in South Africa. In: KALLAWAY, Peter (Ed.). The History of education under apartheid 1948 
- 1994: The doors of learning and culture shall be opened. South Africa: Pearson Education, 2002. p. 94-108.

CHRISTIE, Pam; COLLINS, Colin. Bantu Education: Apartheid ideology and labour reproduction. In: KALLAWAY, Peter (Ed.). Apartheid and education: The education of black South Africans. Johannesburg, South Africa: Ravan Press, 1984. p. 160-183.

Constitution of the Republic of South Africa. As adopted on May 8, 1996, and amended on October 11, 1996. Retrieved from:

<http://www.justice.gov.za/legislation/constitution/SAConstitution-web-eng.pdf>. CORNBLETH, Catherine; WAUGH, Dexter. The great speckled bird. New York: St. Martin's Press, 1995.

DEPARTMENT OF EDUCATION. Curriculum 2005. Learning for the 21st Century. Pretoria. 1997.

ENSLIN, Penelope. The role of fundamental pedagogics in formulation of educational policy in South Africa. In: KALLAWAY, Peter (Ed.). Apartheid and education: The education of Black South Africans. Johannesburg: Ravan Press, 1984, p. 139-147.

FREIRE, Paulo. Pedagogy of the oppressed. New York: The Continuum Publishing Corporation, 1970.

GIROUX, Henry A. Theory and resistance in education: A pedagogy for the opposition. South Hadley, MA: Bergin \& Garvey, 1983.

GOVENDER, S.; MNYAKA, M.; PILLAY, G. New Generation History Grade 12. Durban: New Generation Publishers, 2007.

HARTSHORNE, Ken. Crisis and challenge: Black education 1910-1990. Cape Town, South Africa: Oxford University Press, 1992.

History Syllabus (2000) (Higher Grade), Standard 8-10. [Ministry of Education, South Africa].

HORNER, E. A.; HATTINGH, L.; VAN SCHALKWYK, D.; SELLO, B. Viva History: Learner's Book Grade 10. Florida Hills, South Africa: Vilvia Publishers, 2005.

JANSEN, Jonathan D. Why outcomes-based education will fail: An elaboration. In: JANSEN, Jonathan D.; CHRISTIE, Pam (Eds.). Changing curriculum: Studies on outcomesbased education in South Africa. Kenwyn, South Africa: Juta \& Co. Ltd, 1999. p. 145-156.

JANSEN, Jonathan D; CHRISTIE, Pam (Eds.). Changing curriculum: Studies on outcomesbased education in South Africa. Kenwyn, South Africa: Juta \& Co. Ltd., 1999.

KALLAWAY, Peter (Ed.). Apartheid and education: The education of Black South Africans. Johannesburg, South Africa: Ravan Press, 1984. 
LADSON-BILLINGS, Gloria. From the Achievement Gap to the Education Debt:

Understanding Achievement in U.S. Schools. Educational Researcher, v. 35, n. 7, p. 3-12, 2006.

LODGE, Tom. Black politics in South Africa since 1945. London, England: Longman, 1983.

LOEWEN, James W. Lies my teacher told me. New York: Simon \& Schuster, 1995.

LUBIENSKI, Christopher; NDIMANDE, Bekisizwe S. The politics of market mechanisms in education. In: NDIMANDE, Bekisizwe S.; LUBIENSKI, Christopher (Eds.) Privatization and the education of marginalized children: Policies, impacts and global lessons. New York: Routledge, 2017. p. 3-16.

MARKS, Shula; TRAPIDO, Stanley (Eds.). The politics of race, class, and nationalism in the twentieth century South Africa. London, England: Longman, 1987.

MOLTENO, Frank. The Historical Foundations of the Schooling of Black South Africans. In: KALLAWAY, Peter (Ed.). Apartheid and education: The education of Black South Africans. Johannesburg: Ravan, 1984, p. 45-107.

MOTLHABI, Mokgethi Buti George. The theory and practice of Black resistance to apartheid: A social-ethical analysis. Johannesburg, South Africa: Skotaville, 1985.

MTSHALI, Thokozani. South Africa is losing its memory: Revisiting apartheid throws up the challenges of teaching history in a new way. Sunday Times, October 13, 17, 2002.

NDIMANDE, Bekisizwe S. From Bantu education to the fight for socially just education, Equity \& Excellence in Education, 46 (1), p. 20-35, 2013.

NDIMANDE, Bekisizwe S. Neoliberalism and teacher struggles in post-apartheid public schools. In: VERMA, Rita (Ed.). Be the change: Teacher, activist, global citizen. New York: Peter Lang, 2010. p. 275-288.

NDIMANDE, Bekisizwe S. Perspectives on South African Curriculum 2005. In: AERA/Special Interest Group, Research Focus on Education in the Caribbean \& Africa, J (2), p. 2-3, 2000.

NDIMANDE, Bekisizwe S. Race and resources: Black parents' perspectives on postapartheid South African schools. Race Ethnicity and Education, 15 (4), p. 525-544, 2012.

NDIMANDE, Bekisizwe S.; NEVILLE, Helen. A. Urban education and Black racial identity in South Africa. Urban Education, 2015.

NEKHWEVHA, Fhulu. The influence of Paulo Freire's "Pedagogy of Knowing" on the South African Education Struggle in the 1970's and 1980's. In: KALLAWAY, Peter (Ed). The history of education under apartheid 1948-1994: The doors of learning and culture shall be opened. Cape Town: Maskew Miller Longman, 2002. p. 134-144. 
Nkomo, Mokubung (Ed.). Pedagogy of domination: Toward a democratic education in South Africa. Trenton, New Jersey: Africa World Press Inc., 1990.

POPKEWITZ, Thomas S. Introduction: Critical traditions, modernism, and the 'posts.' In: POPKEWITZ, Thomas S.; FENDLER, Lynn. (Eds.). Critical theories in education: Changing terrains of knowledge and politics. New York: Routledge, 1999. p. 1-13.

SOUTH AFRICAN SCHOOLS ACT. Government Gazette of the Republic of South Africa, n. 84 of 1996, v. 377, November 15, 1996.

SPIVAK, Gayatri Chakravortry. Can the subaltern speak? In: NELSON, Cary; GROSSBERG, Lawrence (Eds.). Marxism and the interpretation of culture. Urbana: University of Illinois Press, 1988. p. 271-313.

YOUNG, Michael F. D. Knowledge and control: New direction for the sociology of education. London: Collier-Macmillan, 1975.

ZEICHNER, Kenneth; DAHLSTROM, Lars. (Eds.). Democratic teacher education reform in Africa: The case of Namibia. Windhoek, Namibia: Gamsberg Macmillan, 2001.

ZINN, Howard. A People's history of the United States: 1492-Present. New York: Harper Collins Press, 2005.

Recebido em: 04/05/2018 Aprovado em: 09/06/2018

Universidade do Estado de Santa Catarina - UDESC Programa de Pós-Graduação em Educação - PPGE

Revista Linhas

Volume 19 - Número 41 - Ano 2018 revistalinhas@gmail.com 